\title{
Exploring the role of strategy instruction on learners' ability to write authentic email requests to faculty
}

Language Teaching Research 2022, Vol. 26(2) 213-237

(C) The Author(s) 2022 Article reuse guidelines: sagepub.com/journals-permissions DOI: |0.|I77/|362|6882|I066997 journals.sagepub.com/home/ltr

@SAGE

\section{Esther Usó-Juan 1 D}

Universitat Jaume I, Spain

\begin{abstract}
This study used a pre-test post-test research design to investigate the role of explicit strategy instruction on Spanish English as a foreign language (EFL) learners' ability to write authentic email requests to faculty. Drawing on Taguchi's (2018) classification of pragmatics learning strategies, the instructional intervention followed a strategy-based approach to help learners understand the form-function-context mapping of email requests in the academic context. A total of IIO naturally occurring email requests for action addressed to three faculty members were collected at two different times: as a pre-test (i.e. before engaging learners in the instructional period), and as a post-test (i.e. after learners' participation in the treatment sessions). Learners' email messages were analysed considering both their appropriateness of use as well the frequency of utilization of different structural (i.e. subject line, openings and closings) and content components (i.e. request strategies and internal request modifiers). Results showed that strategy instruction helped learners write more appropriate email requests after the instructional period. The findings suggest that arming learners with a variety of strategic tools may lead to pragmatic development in actual language use.
\end{abstract}

\section{Keywords}

closings, emails, instructional pragmatics, internal request modifiers, learning strategies, openings, requests

\section{Introduction}

Prior research on email requests during academic consultations has revealed that second language (L2 ${ }^{1}$ ) learners might encounter interlanguage problems, partly because they lack knowledge in pragmalinguistics (i.e. knowledge of linguistic forms and their social

\footnotetext{
Corresponding author:

Esther Usó-Juan, Department of English Studies, Universitat Jaume I, Campus de Riu Sec, Castelló, I 207I, Spain.

Email: euso@uji.es
} 
functions) and sociopragmatics (i.e. knowledge of the sociocultural conventions that guide the use of those linguistic forms) (Biesenbach-Lucas, 2007; Zhu, 2012). Understanding the form-function-context mapping of email requests in the academic context is a challenge faced by L2 learners because these relations are not only intricate, but also vary across cultures (Taguchi, 2015). This suggests that it is necessary to teach learners how to compose email requests that are appropriate in relation to the recipient (i.e. a professor) and the specific request being formulated (i.e. the request imposition). Regrettably, only a few studies have been conducted to address this pedagogical need, and most of them have examined learners' production of email requests by means of elicited methods such as written discourse completion tasks (DCT) (see the review article by Martínez-Flor \& Usó-Juan, 2020), which have been criticized for their artificiality.

In this respect, some researchers (Alcón-Soler, 2015; Nguyen, 2018) have called for studies into the effects of instruction on email requests which go beyond post-test to analyse how learners cope with authentic email messages. Heeding this call, the present study examines the effects of pragmatic instruction on learners' ability to write naturally occurring email requests that are appropriate for an academic context. The instructional framework is based on the taxonomy of pragmatics-learning strategies developed by Taguchi (2018), in an attempt to facilitate the transfer of learned pragmatic knowledge to real academic communication through email. The pragmatic components under study are email structure or framing devices, request strategies and internal request modifiers.

\section{Literature review}

\section{Email requests to faculty}

Research studies have attested to the growing importance of email interaction between students and faculty members, which has largely replaced face-to-face communication. Students write emails to their professors to achieve different communicative functions, among which it seems that requests are the most common (Nguyen, 2018). Because of the asymmetry of the faculty-student relationship, students are required to own pragmatic knowledge to produce status-congruent emails (Biesenbach-Lucas, 2007; Hartford \& Bardovi-Harlig, 1996). Unfortunately, previous research has shown that students may frequently lack adequate pragmatic awareness and competence when writing L2 email requests to faculty (see, to name but a few, Alcón-Soler, 2013; Biesenbach-Lucas, 2007; Chen, 2001, 2006; Economidou-Kogetsidis, 2018; Félix-Brasdefer, 2012).

Chen (2001), for example, compared emails made to faculty by Taiwanese and American graduate students. The author reported that both groups preferred to use query preparatory (e.g. can you) and want statements (e.g. I want / I would like to) to perform their requests, but American students used more internal modifiers, rendering their requests more indirect and polite. Later, Chen (2006) conducted a longitudinal case study of email requests initiated by one Taiwanese graduate student during her two and a half year stay in the USA. The author observed evidence of change as a result of the student's emailing experience: the student's requests changed from want statements to query preparatory strategies and showed evidence of greater politeness, as demonstrated by a higher use of lexico-syntactic modification. 
Also taking a comparative perspective, Biesenbach-Lucas (2007) analysed email requests sent by native speakers (NSs) of English and non-native speakers (NNSs) (from Asian backgrounds) to faculty in relation to requests which varied the level of imposition. Overall, the author found that both groups of students selected more direct strategies for lower imposition requests (requests for appointment and for feedback) and preferred conventionally indirect strategies for the highest imposition requests (requests for an extension of due date), suggesting students' awareness of situational factors. Regarding request modification, the author found that NNSs produced less syntactic modifiers, but more lexical modifiers (especially please) than NSs. Alcón-Soler (2013) also pointed out differences in the amount of lexical and syntactic modifiers employed by British English speakers' and international English speakers' requests in academic cyber-consultations. The former making a wider use of syntactic and lexical modifiers along with the external modifier of disarmers (i.e. to avoid a refusal), whereas the latter relying on the marker please, could and the external modifier of grounders (i.e. to justify the requests).

Several other studies examined the relationship between email directness and the degree of email imposition. Félix-Brasdefer (2012) looked at the type of request and internal modification employed by USA university-level students. Email requests were written in L1 English and L2 Spanish to faculty in four situations that ranged from low to high imposition (i.e. requests for information, validation, feedback or action). The findings revealed that in L1 and L2 requests query preparatory strategies predominated in high imposition requests, whereas direct questions were common in requests with a lower level of imposition. In regard to internal modification of requests, it was found that in comparison with L1 requests, L2 requests included fewer lexical and syntactic modifiers. Unlike Félix-Brasdefer's finding (2012), however, Economidou-Kogetsidis (2018), who examined the email requests of Greek Cypriot L2 learners of English, found the inability of learners to adjust the directness of their emails according to the degree of the email imposition. In her study, direct/bold-on-record strategies predominated in low, medium and high imposition requests.

A few studies have focused on investigating email recipients' perceptions of students' requests (see, amongst others, Economidou-Kogetsidis, 2011, 2016; Hartford \& BardoviHarlig, 1996; Hendriks, 2010; Savić, 2018). In an early study, Hartford and BardoviHarlig (1996) analysed the perlocutionary effect of email requests sent to professors by NSs and NNSs English students. They found that international students used insufficient mitigation in their requests, emphasized their personal needs and lacked status-congruent language, which negatively affected perlocution. Focusing exclusively on email requests written by NNSs, Economidou-Kogetsidis (2011) examined how faculty members perceived some email requests sent by Greek Cypriot learners of English. Results from her study demonstrated that those emails which reflected a preference for direct requests, underused lexical/phrasal downgraders, omitted greetings and closings and included incorrect forms of address were regarded as more impolite or abrupt than others. These findings were confirmed by Savić (2018) in her study of lecturers' perceptions of Norwegian L2 English learners' email requests. The author found that the above-mentioned preferences together with some contextual considerations (e.g. the specificity of the email medium and the challenges of institutional email communication for L2 learners) affected the lecturers' evaluations of email requests. 
Other studies in email perception analysed the effect email requests have on the recipients' judgements of the personality of the senders (Economidou-Kogetsidis, 2016; Hendriks, 2010). Hendriks (2010) investigated English speakers' reactions to variations in request modification in email messages written by Dutch learners of English. Her results showed that the underuse of elaborate lexico-syntactic modifiers may reflect negatively on the sender's agreeableness. In a similar vein, Economidou-Kogetsidis (2016) examined whether direct and unmodified emails written by learners of English were perceived differently by English NS faculty members and Greek Cypriot learners of English. The study demonstrated that there were mismatching perceptions of what an appropriate email request constitutes. Faculty members not only rated the email requests as less polite and abrupt but also judged the email senders' personality as less favourable than learners did.

In summary, aspects of email discourse such as the organizational structure, the level of directness of the request head act as well as the internal request modification play an important role in the politeness of learners' emails. Moreover, they may influence the learners' perceived personality. Thus, there is a need for pragmatic instruction in email literacy to help L2 learners produce status-congruent email requests in academic contexts. This need provides part of the rationale and motivation behind the present study.

\section{Pragmatics instruction on email requests}

Pragmatics focuses on the way people convey and interpret meaning in social contexts. A large body of research has examined the effects of instruction on L2 learners' pragmatic development (for a review, see Taguchi, 2015). The results of work in this area have reported a clear advantage for explicit pragmatic instruction (i.e. providing metapragmatic information) over implicit instruction (i.e. promoting inductive learning via exposure and consciousness raising). Nevertheless, the potential of implicit intervention has also been positively highlighted if it involves activities with a focus on noticing and input processing. Such generalizations have also been provided in the recent review article on the teachability of the speech act of requesting by Martínez-Flor and Usó-Juan (2020). Findings from this review show that many studies have been conducted to identify the instructional effects on L2 requests over the past decades although the bulk of research concentrated on oral L2 requests. In contrast, only very few studies assessed the teachability of L2 email requests (Alcón-Soler, 2015, 2017; Chen, 2015; Ford, 2006; Nguyen, 2018; Nguyen et al., 2015, 2019). Ford (2006) was among the first to assess the instructional effects on composing requestive emails. The study involved a group of mixed L1 students in the USA who were presented with a 50-minute lecture based on rules of netiquette. After comparing the DCT employed for the pre-test, post-test and delayed post-test, the author found that students increased their perlocutionary scores of their email requests significantly on the immediate post-test by employing more downgraders and supportive moves such as preparators, grounders and disarmers as well as using more structural features (i.e. greetings, introduction, closing and signature). However, this treatment effect was not sustained till the delayed post-test, leading the author to conclude that more instructional sessions may be needed for maintaining what has been learned. 
Addressing the interplay between pragmatic instruction and study-abroad, AlcónSoler (2015) investigated Spanish study-abroad students' abilities to mitigate L2 English requests in emails during their stay in England. Both an experimental and a control group were exposed to email requests during the study-abroad year, but only the experimental group received four 20-minute sessions of explicit instruction. The analysis of authentic emails revealed that students in both groups improved their ability to mitigate requests after the stay-abroad period, but those who received instruction made greater improvements in producing appropriate requests. The study also demonstrated individual variation in learners' ability to mitigate requests as well as in the use of email openings and closings, which did not happen in the control group. To understand the reasons behind individual pragmatic trajectories in learners' performance of email requests, Alcón-Soler (2017) reported on the case of two students that received instruction on email requests during the stay-abroad period. The study found that gains from pragmatic instruction interacted with language exposure and individual factors (i.e. personal choice to conform to the target language pragmatic norms) and influenced email request production over time.

In contrast to the studies reviewed above, the remaining studies focused on teaching email requests in the EFL context. Chen (2015) paid attention to Chinese learners' ability to perform email requests to faculty. Following six hours of instruction on email requests, learners made significant progress in their email production and confidence level on the post-test over the pre-test, as measured by a DCT. Moreover, it was also found that learners made marked improvements in using framing moves (i.e. subject, opening, self-identification and closing), but only increased content moves (i.e. request strategies and request support) in small ways. The author explained that framing moves are formulaic in nature, thus being easier for learners to acquire. However, content moves are idiosyncratic in nature (i.e. highly depending on context), thus being more difficult to learn and use.

Finally, in a series of studies targeting Vietnamese EFL learners, Nguyen and colleagues investigated the effect of instruction and feedback in learners' development of request email, elicited by using a DCT (Nguyen, 2018; Nguyen et al., 2015, 2019). The study conducted by Nguyen (2018) found that, after six hours of metapragmatic instruction, the treatment group showed greater pre-to-post-test gains in writing email requests than the control group, and that this improvement was retained when measured again eight months later. Nguyen et al. (2015) examined whether providing written corrective feedback on learners' performance during pragmatics-focused activities could improve their production and recognition of appropriate email requests. During a six-hour training period, two treatment groups received the same instruction but different corrective feedback (i.e. direct feedback vs. metapragmatic feedback), and they were compared with a control group who received only regular instruction. The analysis of learners' performance in the production task revealed that the treatment groups outperformed the control group (although there were no significant differences between the two treatment groups); regarding learners' performance in the recognition task, results indicated that the treatment group who received metapragmatic feedback outperformed those receiving direct feedback and the control group. These findings illustrate that two types of corrective feedback may influence differently on diverse areas of pragmatic competence. In the 
third study, Nguyen et al. (2019) explored whether feedback plus revision led to increased accuracy and fluency in learners' writings. Four groups of learners were set up: three experimental groups and one control group. All four groups received the same metapragmatic instruction on email requests, but the three experimental groups received different feedback treatment: feedback without revision, feedback with one round of revision or feedback with two rounds of revision. The authors reported that the treatment groups showed greater short-term and long-term gains in pragmatic accuracy, but no treatment group outperformed another. However, evidence for the effect of revision on the fluency of learners' pragmatic performance was less clear-cut.

To sum up, although interventional research on request emails is very limited, existing findings suggest that instruction has a positive role in developing learners' pragmatic competence of email requests. Nonetheless, all studies (except for Alcón-Soler, 2015, 2017) examined email requests by means of written DCT, and as Nguyen (2018) concluded in her study, more research is needed that investigates the impact of pragmatic instruction on learners' authentic email messages.

\section{Purpose of the study}

Although the adoption of an explicit and/or implicit type of pragmatics instruction, based on Schmidt's (1993) noticing hypothesis, has been the primary guiding framework, in recent years the strategy-based instructional option has emerged (Taguchi et al., 2019). Addressing strategy instruction in pragmatics has been recommended by Taguchi (2018), who pointed out that it may direct learners' attention to the pragmatic phenomenon in real communicative situations and enhance their pragmatic performance outside the classroom.

Learning strategies are understood as 'specific actions taken by the learner to make learning easier, faster, more enjoyable, more self-directed, more effective, and more transferable to new situations' (Oxford, 1990, p. 8). Taguchi et al. (2019) examined the effectiveness of strategy instruction in helping L2 Japanese and Chinese learners direct their attention to targeted pragmatic features (i.e. conversation opening/closing and indirect meaning). In this study, learners were taught various metacognitive strategies (i.e. referred as 'the construction manager' by Oxford (2011), as cited in Taguchi, 2018, p. 9) and cognitive strategies (i.e. referred as 'the construction worker' by Oxford (2011), as cited in Taguchi, 2018, p. 13). The former involved strategies for managing and controlling L2 (e.g. paying attention to pragmatic issues, monitoring and evaluating the performance), while the latter involved strategies for constructing, transforming and applying L2 knowledge (e.g. activating pragmatic knowledge, reasoning and conceptualizing). Results revealed that, despite the difficulties learners found in applying learning strategies to real life, strategy instruction helped them manage and organize their own learning outside the classroom. Considering this new methodological standpoint, the present study examines whether explicit strategy instruction has a positive impact on learners' ability to write authentic email requests in the academic context. Specifically, the following research questions will be addressed:

- Does strategy instruction improve learners' overall ability to write appropriate email requests to professors? if so, 
- In what features of email discourse (i.e. content lines, openings, closings, request strategies and internal request modifiers) is improvement observed?

\section{Method}

\section{Participants}

The initial participation pool $(n=74)$ comprised two intact classes of Spanish EFL learners majoring in English at a public university in Spain. However, data were analysed only from learners who completed the full instructional period, sent at least one authentic request email before and after the intervention and had an upper-intermediate proficiency level (or B2 level on CEFR scale), as established by the standardized Quick Oxford Placement Test (UCLES, 2001). After all the exclusions, data from 36 participants were included in the final analyses (age range of 19-23; mean age of 20.5; 8 males and 28 females). All participants were undergraduate students, and they were enrolled in an English writing course taught by the researcher of this study, who had extensive experience in pragmatics-focused instruction. Despite learners' common usage of email nowadays, they were completely unfamiliar with the pragmatics of status-congruent email requests in academic settings (i.e. personal communication from instructors).

The recipients of the emails were one male and two female faculty members (including the researcher of this study), who were Spanish speakers with a native-like proficiency level of English and extensive experience in teaching both English language and content courses to university EFL learners. The student-professor relationship was understood by all professors as friendly, but formal and polite. All of them agreed to help collecting data and to forward to the researcher the naturally generated email requests they received from their students. The students were contacted and consented to have their emails analysed for study purposes. To ensure participants' confidentiality, all identifying data were removed from each email prior to analysis.

\section{Instructional intervention}

The study lasted 22 weeks (October 2020 - February 2021) and included an instructional treatment which consisted of three two-hour sessions (i.e. 6 hours in total) spread out over two weeks (weeks 11 and 12). The treatment used models for pragmatics strategy training (Taguchi, 2018; Taguchi et al., 2019), and its design included the following sequence: (1) reflective practice through cognitive strategies, (2) reflective practice through metacognitive strategies and (3) production practice through metacognitive strategies.

a First session: Reflective practice through cognitive strategies. In the first session learners were taught three cognitive strategies, namely (1) activating prior knowledge (i.e. eliciting what learners know about the pragmatics of email requests), (2) reasoning (i.e. analysing and discovering patterns of email requests to faculty), and (3) conceptualizing (i.e. analysing and categorizing email requests into formal, semi-informal or informal). 
In this opening session, learners first completed a writing activity. In this activity, they were asked to write three email requests to the instructor of their writing course (i.e. high power and medium social distance), but the request content ranged from asking for information on course content to proofreading an assignment to requesting a letter of reference (i.e. different imposition forces). Moreover, they brainstormed how variation in the size of the request and familiarity with the email recipient may affect the selection of opening and closing sequences, request strategies and internal request modifiers (i.e. activating prior knowledge). Following this, learners discussed in pairs the pragmatic success and/or failure of their emails and then shared their findings with the whole group. In so doing, the perlocutionary effect of their email requests on the receiver was also discussed. At this stage, they were briefly provided with explanations about the structure of the email request along with a list of request strategies and request modifiers (i.e. reasoning). Finally, learners read some authentic emails, written by English NSs with different levels of formality, and they discussed the reasons for their appropriateness. First, they analysed the discourse structure of the emails, and then they answered some sociopragmatic awareness-raising questions (i.e. questions that focused on those sociopragmatic features in which the request was embedded) and pragmalinguistic ones (i.e. questions that focused on the directness of the request head act and the amount and type of internal request modifiers) (i.e. conceptualizing). In addition, comparisons of how particular request emails could be performed in the learners' L1 were conducted with a view to developing their intercultural awareness (Byram, 1997). These comparisons engendered class discussion on whether they wanted to adhere to the target language norms, retain their L1 identity or blend both perspectives.

In this session, the role of the course instructor was to facilitate the learning of L2 pragmatics by providing resources such as authentic emails and papers that compared request emails written by English NSs and NNSs (see Biesenbach-Lucas, 2007; Hartford \& Bardovi-Harlig, 1996). The findings of these studies showed that, in general, NSs utilize a higher frequency and a wider variety of request modifiers than NNSs, which makes NSs sound more indirect and polite.

b Second session: Reflective practice through metacognitive strategies. The second session aimed at teaching three metacognitive strategies, namely: (1) paying attention to pragmatics-related concepts and setting goals (i.e. directing learners' attention to email requests in their daily life), (2) obtaining resources and implementing plans (i.e. obtaining online resources regarding email requests to faculty), and (3) monitoring and evaluating performance and strategy use (i.e. consciously reflecting on how appropriate their email requests are).

During this second session, learners were first presented with some website addresses from different universities and real professors providing key information and sample emails about how to write appropriate emails to faculty. Following this, learners elaborated a checklist of key issues to address when writing an appropriate request email, including discourse organization, language choices and attention to context and sociocultural norms. These resources provided learners with some basic concepts when writingrequestemails to theirprofessors, so they couldbuildmeaningfulform-function-context connections when analysing and/or producing emails in their academic life (i.e. paying 
attention and setting goals). Once learners knew what to focus on and set goals in attending them, they worked with some authentic emails they brought to the classroom (some appropriate and others not), and they evaluated them against the email checklist they previously elaborated. These email requests were written in English and were sent by them to the course instructor (i.e. obtaining resources and implementing plans). Finally, students were introduced the think-aloud protocol, and after the teacher modelled the technique, some learners demonstrated how they verbalized their thoughts while evaluating their emails in order to help them process the information they learned previously. As a follow-up activity and to promote learners' autonomy, they were encouraged to monitor their email performance for a week and note down some observations regarding aspects they needed to work on more (i.e. monitoring and evaluating performance).

Here, the role of the course instructor was to model good pragmatic behaviour by pointing out those features that may cause pragmatic failure including the following: (1) absence of greetings and closings, (2) the use of inappropriate forms of address (e.g. Hi Teacher), (3) the employment of inappropriate request strategies in high imposition requests (e.g. imperatives) and/or (4) the absence of internal request modifiers.

c Third session: Production practice through metacognitive strategies. After the previous reflective sessions on the importance of writing status-congruent emails to authority figures, this last session focused on production practice through metacognitive strategies. The session required learners to write three email requests to their course instructor (i.e. high power and medium social distance) including a request for face-to-face appointment with the professor, a request for feedback on a written assignment and a request for an extension of a due date (i.e. different imposition forces). These request types were selected because they have been recognized as frequent in student-faculty email interaction (Biesenbach-Lucas, 2007; Nguyen et al., 2015). Here, learners followed a process approach to writing (i.e. continual cycle of planning, drafting, revising, and editing), which they were familiarized with from previous instruction during the semester (Hyland, 2003).

For this activity, learners were asked to set their own goals, plan their writing and selfmonitor their progress toward those goals by using a list of guiding questions provided to them, including (Taguchi, 2018, p. 13): (1) Did I understand the form-function connection? (2) Did I understand the contextual information? (3) What did I write when I produced the email request and why? (4) Was I able to convey my intention successfully? (5) Are there other ways to open and close the email? and (6) Are there other request forms that I could have used? Immediately after writing the emails, learners were asked to rate on a 5 -point Likert-type scale $(1=$ no confidence, $5=$ high confidence $)$ their confidence when judging the appropriateness of their emails and give reasons for their choice by referring to the discourse organization of the email as well as the language used. By justifying their language choices, learners could develop a deeper understanding of how to write request emails from a pragmatic perspective.

The learning outcome was revised by the course instructor and feedback was given on learners' performance during a subsequent class. Following Nguyen et al. (2015), the produced emails were returned with underlining and metapragmatic feedback, in the form of comments/questions, provided in the margins. Feedback focused on the 
discourse organization of the email message, request strategies, request modifiers and general language usage. Feedback was also provided on the learners' comments regarding the appropriateness of their request emails. In the final session, the instructor took the role of advisor rather than the formal role of instructor.

\section{Data collection procedure}

Learners' emails sent to their professors naturally were collected at two different times: as a pre-test (T1), before engaging learners in the instructional period (from week 1 to week 10) and as a post-test (T2), after learners' participation in the treatment sessions (from week 13 to week 22). A total of 110 emails containing student-initiated requests were selected from a larger corpus since not all emails contained requests. Out of the 110 email requests, 55 email exchanges were selected as pre-test and 55 as post-test. To ensure comparability between pre-test and post-test data, all emails were written in L2 English, and they represented requests for actions, that is, requests that implied some kind of action on the part of the professor such as providing course materials, uploading presentations, setting time for revising exams, among others.

\section{Data analysis}

In order to answer the first research question, the appropriateness of each email was rated on a five-point Likert scale, with a value of 5 being 'appropriate', 4 'adequately appropriate', 3 'not so appropriate', 2 'mostly inappropriate', and 1 'completely inappropriate' (adopted from Nguyen et al., 2015). The highest possible grade for each email was 5. The assessment focused on four areas: (1) goal (i.e. whether the communicative intent was achieved by using a range of semantic moves), (2) register (i.e. whether it was appropriate for the context as evidenced in the level of formality, politeness, word choice and tone), (3) overall discourse (i.e. whether it was well-organized and coherent) and (4) language use (i.e. whether there was a correct usage of grammar, vocabulary and punctuation).

To answer the second research question, learners' email requests were analysed with regard to the presence of different discourse features included in their organizational structure, the directness of the request head act and the amount and type of internal request modifiers. Due to limited class time, it was not possible to target external request modification as part of the instructional sessions. The email structure or framing devices included the subject line, which conveys the core content of the email and the opening and closing moves of the email, which serve to initiate and end the conversation, respectively, and may influence the appropriateness of the message (Bou-Franch, 2006). Although optional, these framing devices contribute to the physical layout of the message, and they help give the message a positive tone (Chen, 2015). The subject lines, following Chen (2015), were classified in terms of concreteness (i.e. whether they were abstract or concrete) and the openings and closings in terms of completeness (i.e. whether they included all categories needed for a formal opening and closing), as shown in Table 1.

Requests were analysed according to request strategies and internal modification, which were classified following the coding scheme proposed by Félix-Brasdefer (2012). 
Table I. Structural features of email requests to faculty.

\begin{tabular}{|c|c|}
\hline Structural feature & Example \\
\hline \multicolumn{2}{|c|}{ Subject (Description of the topic of a message): } \\
\hline Zero marking & $\mathrm{X}$ \\
\hline Abstract & Hi, I'm Carla \\
\hline Concrete & Deadline extension \\
\hline \multicolumn{2}{|c|}{ Opening (Realized by greetings and self-identifications): } \\
\hline Zero marking & $x$ \\
\hline Incomplete (one component missing) & Dear Professor $X$ \\
\hline Complete (all components employed) & Dear Professor X. I'm . . . from your . . . class \\
\hline \multicolumn{2}{|c|}{ Closing (Realized by pre-closing, complementary close and signature): } \\
\hline Zero marking & $\mathrm{x}$ \\
\hline Incomplete (one component missing) & Thank you. Carla \\
\hline Complete (all components employed) & Thank you. Sincerely. Carla Soro \\
\hline
\end{tabular}

Source. Adapted from Chen, 2015.

Request strategies, which provide the main communicative goal of the message (Chen, 2015), were categorized into Direct, Conventionally Indirect and Non-conventionally Indirect. However, in the final analyses non-conventionally indirect requests were excluded because they were not present in the email corpus of this study.

The analysis of the request head act also included an examination of the internal request modifiers. These modifiers refer to those syntactic and lexical devices that appear within the same request head act and serve to mitigate the request imposition. The analysis of lexical modifiers included: (1) the marker 'please', (2) downtoners (i.e. to state the possibility of not complying with the request), (3) consultative devices (i.e. to seek the addressee cooperation) and (4) understaters (i.e. to downplay the demanding action). Moreover, the analysis of syntactic modifiers involved the use of the conditional and multiple syntactic combination of tense, aspect and/or conditional. Following Félix-Brasdefer (2012, p. 100), the type 'syntactic combination' was coded as such when it included two or more of the following syntactic modifiers: conditional form ('could' vs. 'can'), past tense ('I was wondering' vs. 'I am wondering') or progressive aspect ('I am wondering' vs. 'I wonder'). Table 2 shows the request strategies and internal request modifiers.

The whole analysis was first conducted individually by the researcher, and then $30 \%$ of the email messages were coded by another researcher with experience in coding requests strategies. All discrepancies were discussed and solved.

\section{Statistical analysis}

Data were analysed with the Statistical Package for the Social Sciences (SPSS) version 22.0. First, a descriptive analysis of all variables was conducted, calculating measures of central tendency and dispersion (i.e. mean, standard deviation, median, minimum and 
Table 2. Request strategies and internal request modifiers.

\begin{tabular}{|c|c|}
\hline Strategies & Devices \\
\hline \multicolumn{2}{|l|}{ Direct (request strategy): } \\
\hline Imperatives & Please, give me ... \\
\hline Performatives & I am asking you to . . . \\
\hline Want statements & I want you to ... \\
\hline Need statements & I need ... \\
\hline Direct questions & When is ...? \\
\hline Like/appreciate statements & I would appreciate . . . \\
\hline Expectation statements & I hope... \\
\hline \multicolumn{2}{|l|}{ Conventionally indirect (request strategy): } \\
\hline Query preparatory & Could you . . ? Would you? \\
\hline \multicolumn{2}{|l|}{ Lexical modifiers (internal modifier): } \\
\hline Politeness marker 'please' & Please, . \\
\hline Downtoners & possibly / maybe / perhaps \\
\hline Consultative devices & Do you think . . ? / Do you mind . . ? \\
\hline Understaters & a little / a minute / just \\
\hline \multicolumn{2}{|l|}{ Syntactic modifiers (internal modifier): } \\
\hline Conditional & Could (for 'can') you . . .? \\
\hline $\begin{array}{l}\text { Multiple syntactic combination (conditional / } \\
\text { past tense / progressive aspect) }\end{array}$ & I was wondering if you could. . . \\
\hline
\end{tabular}

maximum) for quantitative variables, while for categorical variables, frequencies and percentages were determined. The Mann-Whitney U non-parametric test was used to compare quantitative variables between $\mathrm{T} 1$ and $\mathrm{T} 2$ since data did not fit a normal distribution (Kolmogorov-Smirnov test, $\mathrm{p}=0.000$ ). The Pearson's chi-square test was used to compare categorical variables between $\mathrm{T} 1$ and T2. Statistical differences were considered significant at $\mathrm{p} \leqslant 0.05$.

\section{Results}

\section{Effects of instruction on learners' ability to write email requests to professors}

Table 3 presents descriptive statistics of learners' overall ability when writing email requests before and after instruction and summarizes Mann-Whitney test results. Findings show an important improvement in learners' ability to write appropriate email requests in $\mathrm{T} 2(\mathrm{M}=4.16, \mathrm{SD}=0.570)$ as compared to $\mathrm{T} 1(\mathrm{M}=2.82, \mathrm{SD}=0.512)$. The Mann-Whitney test was run to compare means, and the results revealed a statistically significant difference between T1 and T2 $(U=166.50, p=0.000)$. 
Table 3. Descriptive statistics on learners' overall performance in TI and T2; Mann-Whitney Test results.

\begin{tabular}{lllllllll}
\hline Time & N & Mean & SD & Median & Min & Max & U & P \\
\hline TI & 55 & 2.82 & 0.512 & 3 & 2 & 4 & & \\
T2 & 55 & 4.16 & 0.570 & 4 & 3 & 5 & 166.50 & $0.000^{*}$ \\
\hline
\end{tabular}

Notes. $\mathrm{N}=$ sample size. $\mathrm{SD}=$ standard deviation. Min $=$ minimum. Max $=$ maximum. $* p<0.05$.

Example (1) illustrates an email message one learner wrote to a professor to request a deadline extension before receiving the treatment on writing status-congruent email requests. This email request was given a score of 3 (i.e. not so appropriate) because a number of pragmatic infelicities were identified.

(1) [Subject: About the writing task]

Dear + first name,

I am writing to tell you I need extra days to complete the writing task I have to submit next week. This task is taking me much longer than I expected. Also, I work four days a week, and I don't think it is possible for me to complete it with the time I have left before the submission date. I hope you'll give me a week extension to finish it properly.

Thanks

(Full name of the student)

Regarding the framing sequence, the subject line was classified as 'abstract' because it did not reflect the content of the email, that is, a request for a deadline extension. The opening sequence was coded in the study as 'incomplete.' Here, the instructor was addressed using the deference term 'dear' followed by the instructor's first name, which is less formal than expected given the relatively high Power Distance Index (57) that Spain has according to Hofstede and Hofstede (2005). A more formal way to express deference politeness could have been achieved using the deference term 'dear' followed by the correct academic title and the professor's last name/full name. In addition, the sender's self-identification was not included, assuming that the professor would recognize the learner, which does not always happen when courses have a high number of students per class, as it happens in Spain (Bou-Franch, 2006). Finally, the closing sequence was also classified as incomplete. Although the sequence included a pre-closing/thanks statement to express gratitude for the future granting of the request and a signature line, the complementary close (e.g. Sincerely, Best wishes, etc.) was missing.

As for the request sequence, this was realized by two direct strategies, particularly a need statement (i.e. I need extra days . . .) and an expectation statement (i.e. I hope you'll ....), which could be considered too direct given the high imposition of the request. Moreover, the request strategies did not rely on the use of internal mitigation, but on request grounders (i.e. justifications) that were based on personal rather than academic reasons. 
However, after the instructional period, the email writing practice of the same learner improved markedly, as seen in example (2), which was rated 5 (i.e. appropriate). Here, the subject line was coded as 'concrete' because it provided specific details about the email content, and the opening and closing sequences were categorized as 'complete' because they not only included all basic elements of each sequence but also were written in an appropriate way. As for the selected request form, a combination of syntactic modifiers (i.e. aspect and conditional) and a lexical modifier (i.e. possibly) were used to express a conventionally indirect request.

(2) [Subject: Problems uploading final assignment]

Dear Professor + first name + surname,

My name is (full name of the student), and I am one of your students in (name of the course). I am writing to tell you that I could not upload the final assignment on the virtual classroom because my file is over the size limit (100MB). I was wondering if you could possibly increase the file size to solve this problem.

Thanks for your time and consideration.

Best,

(Full name of the students)

PS. I attach a screenshot with the message that appears when I try to upload my file.

In summary, results related to the first research question revealed that strategy instruction resulted in a strong effect on the learning of how to write appropriate emails to faculty, as found in the learners' superior performance in T2 compared with that in T1. More specifically, instruction allowed the learners to progress from a 'not so appropriate' level in T1 (median score: 3) to an 'adequately appropriate' level in T2 (median score: 4).

\section{Aspects of email requests improved}

To explore the previous significant findings, further analyses were carried out to identify in which aspects of the email discourse an improvement was found. Thus, the analysis focused on learners' email subject lines, opening and closing sequences as well as request strategies and internal request modifiers.

a Analysis of subject lines. The email subject lines were coded as zero (i.e. when a subject line was missing), abstract (i.e. when the subject line did not reflect the purpose of the email), or concrete (i.e. when the subject line reflected the purpose of the email). Table 4 reports descriptive statistics of subject lines and shows the results of Pearson's Chi-Square test.

As observed in Table 4, although before instruction $69.1 \%$ (or 38/55) of the subject lines supplied by learners were concrete, $29.1 \%$ (or 16/55) of them were abstract and $1.8 \%$ (or 1/55) were empty. Examples (3)-(5) show instances of email subject lines that were coded as abstract because they did not reflect the theme of the email requests. Example (3) was the subject line of an email asking for deadline extension, example (4) 
Table 4. Descriptive statistics of subject lines in TI and T2; Chi-Square test results.

\begin{tabular}{lllrrr}
\hline Subject types & Time & $\boldsymbol{f}$ & $\%$ & $\chi^{2}(1)$ & P \\
\hline Zero & TI & $1 / 55$ & 1.8 & & \\
\multirow{3}{*}{ Abstract } & T2 & $0 / 55$ & 0.0 & 1.009 & 0.315 \\
& TI & $16 / 55$ & 29.1 & & \\
Concrete & T2 & $1 / 55$ & 1.8 & 15.655 & $0.000^{*}$ \\
& TI & $38 / 55$ & 69.1 & & \\
& T2 & $54 / 55$ & 98.2 & 17.005 & $0.000^{*}$ \\
\hline
\end{tabular}

Note. $* p<0.05$.

concerned uploading a presentation file, and example (5) involved modifying a test score.

(3) Subject: I work

(4) Subject: Activities

(5) Subject: Problem

After instruction, however, concrete subjects increased to $98.2 \%$ (or 54/55), the difference being statistically significant $\left(\chi^{2}(1)=17.005, \mathrm{p}=0.000\right)$. Examples $(6)-(8)$ show instances of concrete email subject lines, echoing the topic of the emails.

(6) Subject: Sending references for the next assignment

(7) Subject: Request for an exam confirmation letter

(8) Subject: Revising my writing assignment mark

b Analysis of opening sequences. The opening sequences generally include two moves: greetings and self-identification (i.e. student's name and institution/course information) (Bou-Franch, 2011). Thus, openings were coded as zero when emails did not include one, as incomplete, when one move was missing and as complete when they included the two moves. Table 5 displays descriptive statistics of opening sequences and reports ChiSquare test results. As seen in the table, before receiving instruction, only $16.4 \%$ (or 9/55) of the emails involved a complete opening, whereas after the intervention, this percentage dramatically increased to $90.9 \%$ (or 50/55), the difference being statistically significant $\left(\chi^{2}(1)=61.452, \mathrm{p}=0.000\right)$.

The next line of analysis provides further information in describing the choice of moves in the opening sequences. Table 6 describes the most common constructions chosen by learners before and after the treatment. Concerning the first move, $96.4 \%$ (or $53 / 55$ ) of the learners' emails before instruction contained greeting strategies although they displayed different degrees of formality towards the professors. About $50.8 \%$ (or $27 / 53$ ) of the greetings were realized by the deference form 'dear' + title +last name/full 
Table 5. Descriptive statistics of opening sequences in TI and T2; Chi-Square test results.

\begin{tabular}{lllrrl}
\hline $\begin{array}{l}\text { Opening } \\
\text { types }\end{array}$ & Time & $\boldsymbol{f}$ & $\%$ & $\chi^{2}(\mathrm{I})$ & $\mathrm{P}$ \\
\hline Zero & TI & $2 / 55$ & 3.6 & & \\
& T2 & $0 / 55$ & 0.0 & 2.037 & 0.154 \\
Incomplete & TI & $44 / 55$ & 80.0 & & \\
& T2 & $5 / 55$ & 9.1 & 55.975 & $0.000^{*}$ \\
Complete & TI & $9 / 55$ & 16.4 & & \\
& T2 & $50 / 55$ & 90.9 & 61.452 & $0.000^{*}$ \\
\hline
\end{tabular}

Note. $* p<0.05$.

Table 6. Openings in $\mathrm{TI}$ and $\mathrm{T} 2$.

\begin{tabular}{|c|c|c|c|c|}
\hline \multirow[t]{2}{*}{ Combinations } & \multicolumn{2}{|l|}{ TI } & \multicolumn{2}{|l|}{$\mathrm{T} 2$} \\
\hline & $f$ & $\%$ & $f$ & $\%$ \\
\hline Dear + Mr/Mrs/Miss/Ms + last name/full name & 14 & 26.4 & 0 & 0.0 \\
\hline Dear+Professor+last name/full name+self-identification & 4 & 7.5 & 30 & 54.5 \\
\hline Dear+Professor+last name/full name & 9 & 16.9 & 0 & 0.0 \\
\hline Dear + full name + self-identification & 3 & 5.6 & 10 & 18.1 \\
\hline Dear+first name & 3 & 5.6 & 0 & 0.0 \\
\hline Good morning/afternoon/night + first name & 6 & 11.3 & 0 & 0.0 \\
\hline Good morning/afternoon/night & 1 & 1.8 & 0 & 0.0 \\
\hline Hello+Professor+last name/full name+self-identification & 2 & 3.7 & 10 & 18.1 \\
\hline Hello+first name & 6 & 11.3 & 5 & 9.0 \\
\hline Hello & 2 & 3.7 & 0 & 0.0 \\
\hline $\mathrm{Hi}+$ first name & 2 & 3.7 & 0 & 0.0 \\
\hline $\mathrm{Hi}$ & 1 & 1.8 & 0 & 0.0 \\
\hline Total & 53 & 100.0 & 55 & 100.0 \\
\hline
\end{tabular}

Note. Percentages in the table do not sum to 100.0 as a result of rounding.

name. Notice, however, that the correct academic title (i.e. Professor) was employed in only $24.4 \%$ (or $13 / 53$ ) of the emails, while $26.4 \%$ (or $14 / 53$ ) of them used a wrong academic title (i.e. $M r / M r s / M i s s / M s$ ). By contrast, 48.5\% (or 26/53) of the students' emails employed varied and more informal constructions, indicating the students' uncertainty about how to greet their instructors. Examples (9)-(10) present some of those constructions. Although (9) could result from a student-professor close relationship, (10) is far too informal for writing to a faculty member and could be considered disrespectful. Moreover, the second part of the opening sequence, that is, the sender's self-identification, was solely observed in $16.8 \%$ (or 9/53) of the emails. It is interesting to note that these emails, except for two, only included the student's full name and omitted the information about the class. Example (11) illustrates an instance of incomplete self-identification. 
Table 7. Descriptive statistics of closing sequences in TI and T2; Chi-Square test results.

\begin{tabular}{llllll}
\hline Closing types & Time & $\boldsymbol{f}$ & $\%$ & $\chi^{2}(\mathrm{I})$ & $\mathrm{P}$ \\
\hline Zero & TI & $1 / 55$ & 1.8 & & \\
\multirow{3}{*}{ Incomplete } & T2 & $0 / 55$ & 0 & 2.037 & 0.154 \\
& TI & $31 / 55$ & 56.4 & & \\
Complete & T2 & $7 / 55$ & 12.7 & 23.158 & 0.00 * $^{*}$ \\
& TI & $23 / 55$ & 41.8 & & \\
& T2 & $48 / 55$ & 87.3 & 26.557 & $0.000^{*}$ \\
\hline
\end{tabular}

Note. $* p<0.05$.

(9) Hello (teacher's first name)

(10) $\mathrm{Hi}$

(11) My name is (student's full name) and I am in your class.

Nonetheless, after the instructional intervention, 100\% (or 55/55) of the students' emails involved a greeting expression and $90.9 \%$ (or 50/55) of them contained the sender's selfidentification. As for the choice of forms of greetings, 54.4\% (or 30/55) of the emails included the deference form 'dear'+academic title+last name/full name+self-identification. All other combinations occurred less frequently or not at all. See example (12) for a complete greeting sequence.

(12) Dear Professor (Professor's full name). I am (student's name) and I am enrolled in your course (name of the course).

c Analysis of closing sequences. Three moves are commonly used in closing sequences: a pre-closing statement, a complementary close and a signature line (Codina-Espurz \& Salazar-Campillo, 2019). Thus, closings were coded as zero when emails did not include one, as incomplete, when one move was missing and as complete when they included the three moves. Table 7 shows descriptive statistics of closing sequences and reports ChiSquare test results. The results indicate that prior to instruction $41.8 \%$ (or 23/55) of the emails included a complete closing. However, after instruction, the complete closing sequences increased to $87.3 \%$ (or $48 / 55)$ with a statistically significant difference $\left(\chi^{2}(1)\right.$ $=26.557, \mathrm{p}=0.000)$.

The following line of analysis specifies the choice of moves in the closing sequences. Table 8 illustrates the particular formulas chosen before and after the treatment. Prior to instruction, $41.8 \%$ (or 23/54) of the students' emails indicated a preference for a complete closing realization, that is, pre-closing + complementary close + signature. The rest either included a combination of two moves (occurring in $40 \%$ or $22 / 54$ emails) or presented a single closing move (occurring in $16.3 \%$ or $9 / 54$ emails). Instruction, however, brought about important changes. In fact, complete closings were identified in $87.3 \%$ (or $48 / 55$ ) emails while the rest of the closing formulas occurred $12.7 \%$ (or 7/55). A typical complete closing realization can be seen in example (13). 
Table 8. Types of closings in $\mathrm{TI}$ and $\mathrm{T} 2$.

\begin{tabular}{|c|c|c|c|c|}
\hline \multirow[t]{2}{*}{ Combinations } & \multicolumn{2}{|l|}{ TI } & \multicolumn{2}{|l|}{$\mathrm{T} 2$} \\
\hline & $f$ & $\%$ & $f$ & $\%$ \\
\hline $\begin{array}{l}\text { Pre-closing }+ \text { complementary } \\
\text { close }+ \text { signature }\end{array}$ & 23 & 41.8 & 48 & 87.3 \\
\hline Pre-closing + complementary close & 2 & 3.6 & 0 & 0.0 \\
\hline Pre-closing + signature & 10 & 18.2 & 0 & 0.0 \\
\hline Pre-closing & 2 & 3.6 & I & 1.8 \\
\hline Complementary close + signature & 10 & 18.2 & 5 & 9.1 \\
\hline Complementary close & 2 & 3.6 & 0 & 0.0 \\
\hline Signature & 5 & 9.1 & I & 1.8 \\
\hline Total & 54 & 100.0 & 55 & 100.0 \\
\hline
\end{tabular}

Note. Percentages in the table do not sum to 100.0 as a result of rounding.

(13) Thank you for taking the time to consider my request.

Best wishes,

(student's full name)

d Analysis of request strategies. Request strategies were categorized into direct and conventionally indirect strategies. Non-conventionally indirect requests were not present neither in T1 nor in T2. Table 9 displays descriptive statistics of requests strategies and provides the Mann-Whitney test results. Frequency analysis reveals that the total number of request strategies (i.e. direct strategies plus conventionally indirect strategies) was 78 in $\mathrm{T} 1(\mathrm{M}=1.42, \mathrm{SD}=0.686)$ and 60 in $\mathrm{T} 2(\mathrm{M}=1.09, \mathrm{SD}=0.290)$, the difference being statistically significant $(\mathrm{U}=1145.0, \mathrm{p}=0.002)$. Regarding the subtype of direct strategies, learners used 60 strategies in $\mathrm{T} 1(\mathrm{M}=1.09, \mathrm{SD}=0.8)$ and only 8 strategies in $\mathrm{T} 2(\mathrm{M}=0.15, \mathrm{SD}=0.356)$, with the difference being very statistically significant (U $=494.0, \mathrm{p}=0.000)$. Of all the direct strategies produced by learners, there were statistically significant differences $(\mathrm{p}=0.000)$ in the use of like/appreciate statements (Time 1: $\mathrm{M}=0.6, \mathrm{SD}=0.564 \mathrm{vs}$. Time $2: \mathrm{M}=0.07, \mathrm{SD}=0.262$ ) and performatives (Time 1 : $\mathrm{M}=0.22, \mathrm{SD}=0.498$ vs. Time $2: \mathrm{M}=0.05, \mathrm{SD}=0.229)$. The other direct strategies were infrequently utilized by learners in both times, and results did not reach statistical significance $(p>0.05)$. Finally, with respect to the distribution of conventionally indirect strategies (i.e. query preparatory), learners increased their use from 18 strategies in $\mathrm{T} 1(\mathrm{M}=0.33, \mathrm{SD}=0.474)$ to 52 strategies in $\mathrm{T} 2(\mathrm{M}=0.95, \mathrm{p}=0.356)$, the difference being high and significant $(\mathrm{U}=614.5, \mathrm{p}=0.000)$. The typical sub-strategies of like/ appreciate statements and performatives used in T1 are illustrated in examples (14) and (15) respectively.

(14) I would like to know your opinion on the attached essay. (T1)

(15) I write to ask for the photocopies you gave in class last Wednesday. (T1) 
Table 9. Descriptive statistics of request strategies in TI and T2; Mann-Whitney test results.

\begin{tabular}{|c|c|c|c|c|c|c|c|c|c|}
\hline Request strategies & Time & $\mathrm{N}$ & Mean & SD & Median & Min & Max & $\cup$ & $P$ \\
\hline \multicolumn{10}{|l|}{ Direct: } \\
\hline \multirow[t]{2}{*}{ Imperatives } & TI & 6 & 0.11 & 0.315 & 0 & 0 & I & | 375.0 & 0.052 \\
\hline & $\mathrm{T} 2$ & I & 0.02 & 0.135 & 0 & 0 & 1 & & \\
\hline \multirow[t]{2}{*}{ Performatives } & TI & 12 & 0.22 & 0.498 & 0 & 0 & 2 & 1237.5 & $0.001 *$ \\
\hline & $\mathrm{T} 2$ & 0 & 0.05 & 0.229 & 0 & 0 & I & & \\
\hline \multirow[t]{2}{*}{ Want statements } & TI & 3 & 0.05 & 0.229 & 0 & 0 & 1 & | 457.5 & 0.311 \\
\hline & $\mathrm{T} 2$ & I & 0.02 & 0.135 & 0 & 0 & I & & \\
\hline \multirow[t]{2}{*}{ Need statements } & TI & 1 & 0.02 & 0.135 & 0 & 0 & 1 & 1485.0 & 0.317 \\
\hline & $\mathrm{T} 2$ & 0 & 0.04 & 0.189 & 0 & 0 & I & & \\
\hline \multirow[t]{2}{*}{ Direct questions } & TI & 2 & 0.04 & 0.189 & 0 & 0 & 1 & | 485.0 & 0.560 \\
\hline & $\mathrm{T} 2$ & I & 0.02 & 0.135 & 0 & 0 & I & & \\
\hline \multirow{2}{*}{$\begin{array}{l}\text { Like/appreciate } \\
\text { statements }\end{array}$} & TI & 33 & 0.6 & 0.564 & I & 0 & 2 & 766.0 & $0.000 *$ \\
\hline & $\mathrm{T} 2$ & 3 & 0.07 & 0.262 & 0 & 0 & I & & \\
\hline \multirow{2}{*}{$\begin{array}{l}\text { Expectation } \\
\text { statements }\end{array}$} & TI & 3 & 0.11 & 0.315 & 0 & 0 & 1 & 1457.5 & 0.311 \\
\hline & $\mathrm{T} 2$ & I & 0.01 & 0.135 & 0 & 0 & 1 & & \\
\hline \multirow[t]{2}{*}{ Sub-total } & TI & 60 & 1.09 & 0.8 & I & 0 & 3 & 494.0 & $0.000 *$ \\
\hline & $\mathrm{T} 2$ & 8 & 0.15 & 0.356 & 0 & 0 & 1 & & \\
\hline \multicolumn{10}{|l|}{ Conventionally indirect: } \\
\hline \multirow[t]{2}{*}{ Query preparatory } & $\mathrm{TI}$ & 18 & 0.33 & 0.474 & 0 & 0 & 1 & 614.5 & $0.000 *$ \\
\hline & $\mathrm{T} 2$ & 52 & 0.95 & 0.356 & I & 0 & 2 & & \\
\hline \multirow[t]{2}{*}{ Total } & TI & 78 & 1.42 & 0.686 & I & 1 & 4 & II45.0 & $0.002 *$ \\
\hline & $\mathrm{T} 2$ & 60 & 1.09 & 0.290 & I & I & 2 & & \\
\hline
\end{tabular}

Notes. $\mathrm{N}=$ sample size. $\mathrm{SD}=$ standard deviation. Min $=$ minimum. Max $=$ maximum. $* p<0.05$.

e Analysis of internal request modifiers. In addition to examining the request strategies used by learners in their emails, the internal modification that served to mitigate the force of the requests was also analysed. Internal modifiers were categorized into lexical and syntactic downgraders. Table 10 presents descriptive statistics of internal request modifiers by type and summarizes the Mann-Whitney test results. Frequency analysis reveals that the total number of request modifiers (i.e. lexical plus syntactic modifiers) was 27 in $\mathrm{T} 1(\mathrm{M}=0.49, \mathrm{SD}=0.690)$ and 83 in $\mathrm{T} 2(\mathrm{M}=1.51, \mathrm{SD}=$ $0.717)$, the difference being high and significant $(U=500.0, p=0.000)$, indicating that before instruction many learners lacked a wide range of linguistic resources to mitigate their requests internally. With regard to the learners' use of lexical modifiers, learners increased their use from 9 in $\mathrm{T} 1(\mathrm{M}=0.16, \mathrm{SD}=0.373)$ to 35 in $\mathrm{T} 2(\mathrm{M}=$ $0.64, \mathrm{SD}=0.620)$, the difference being strong and significant $(\mathrm{U}=889.5, \mathrm{p}=$ 0.000). Of all four types of lexical modifiers that appear in the data, there were significant differences $(p<0.05)$ in the use of downtoners (e.g. possibly, maybe) (Time 1: $\mathrm{M}=0.04, \mathrm{SD}=0.189$ vs. Time $2: \mathrm{M}=0.49, \mathrm{SD}=0.573)$ and consultative devices (e.g. do you think . . ; do you mind . . .) (Time 1: $\mathrm{M}=0, \mathrm{SD}=0$ vs. Time $2: \mathrm{M}=0.07, \mathrm{SD}=0.262)$. 
Table 10. Descriptive statistics of internal request modifiers in TI and T2; Mann-Whitney test results.

\begin{tabular}{|c|c|c|c|c|c|c|c|c|c|}
\hline Modifiers & Time & $\mathrm{N}$ & Mean & SD & Median & Min & Max & $U$ & $\mathrm{P}$ \\
\hline \multicolumn{10}{|l|}{ Lexical modifiers: } \\
\hline \multirow[t]{2}{*}{ 'please' } & TI & 7 & 0.13 & 0.336 & 0 & 0 & I & 1402.5 & 0.187 \\
\hline & $\mathrm{T} 2$ & 3 & 0.05 & 0.229 & 0 & 0 & I & & \\
\hline \multirow[t]{2}{*}{ Downtoners } & $\mathrm{TI}$ & 2 & 0.04 & 0.189 & 0 & 0 & I & 878.0 & $0.000 *$ \\
\hline & $\mathrm{T} 2$ & 27 & 0.49 & 0.573 & 0 & 0 & 2 & & \\
\hline \multirow[t]{2}{*}{ Consultative devices } & TI & 0 & 0 & 0 & 0 & 0 & 0 & 1402.5 & $0.043^{*}$ \\
\hline & $\mathrm{T} 2$ & 4 & 0.07 & 0.262 & 0 & 0 & I & & \\
\hline \multirow[t]{2}{*}{ Understaters } & TI & 0 & 0 & 0 & 0 & 0 & 0 & 1485.0 & 0.317 \\
\hline & $\mathrm{T} 2$ & 1 & 0.02 & 0.135 & 0 & 0 & I & & \\
\hline \multirow[t]{2}{*}{ Sub-total } & TI & 9 & 0.16 & 0.373 & 0 & 0 & 1 & 889.5 & $0.000 *$ \\
\hline & $\mathrm{T} 2$ & 35 & 0.64 & 0.620 & I & 0 & 2 & & \\
\hline \multicolumn{10}{|l|}{ Syntactic modifiers: } \\
\hline \multirow[t]{2}{*}{ Conditional } & TI & 7 & 0.13 & 0.336 & 0 & 0 & I & | 402.5 & 0.305 \\
\hline & $\mathrm{T} 2$ & II & 0.20 & 0.404 & 0 & 0 & I & & \\
\hline \multirow[t]{2}{*}{ Combination } & TI & II & 0.20 & 0.404 & 0 & 0 & I & 797.5 & $0.000 *$ \\
\hline & $\mathrm{T} 2$ & 37 & 0.67 & 0.474 & I & 0 & 1 & & \\
\hline \multirow[t]{2}{*}{ Sub-total } & TI & 18 & 0.33 & 0.511 & 0 & 0 & 2 & 684.0 & $0.000 *$ \\
\hline & $\mathrm{T} 2$ & 48 & 0.87 & 0.336 & 0 & 0 & 2 & & \\
\hline \multirow[t]{2}{*}{ Total } & TI & 27 & 0.49 & 0.690 & 0 & 0 & 3 & 500.0 & $0.000 *$ \\
\hline & $\mathrm{T} 2$ & 83 & 1.51 & 0.717 & I & 0 & 3 & & \\
\hline
\end{tabular}

Notes. $\mathrm{N}=$ sample size. $\mathrm{SD}=$ standard deviation. Min $=$ minimum. Max $=$ maximum. $* p<0.05$.

Syntactic modifiers exhibited a similar trend as learners used only 18 syntactic modifiers in $\mathrm{T} 1(\mathrm{M}=033, \mathrm{SD}=0.511)$ and this number increased to 48 in $\mathrm{T} 2(\mathrm{M}=0.87, \mathrm{SD}$ $=0.336)$, the difference being high and significant $(\mathrm{U}=684.0, \mathrm{p}=0.000)$. Of the two types of syntactic modifiers that learners employed, there were significant differences ( $\mathrm{p}$ $=0.000$ ) in the use of the combination of syntactic modifiers (e.g. I was wondering if I could . . ) (Time $1: \mathrm{M}=0.20, \mathrm{SD}=0.404$ vs. Time $2: \mathrm{M}=0.67, \mathrm{SD}=0.474)$. Example (16) illustrates a typical pattern that learners followed after instruction.

(16) I was wondering if you could possibly arrange an appointment slot for me. (T2)

Overall, the results related to the second research question, showed that learners benefited from strategy instruction in different aspects of email discourse. Regarding the email structure or framing devices, learners produced more concrete subject lines and more complete greetings and closing sequences after instruction. As for the request strategies, instruction helped learners to mitigate the tone of the email requests using both more conventionally indirect request strategies (i.e. query preparatory) as well as more lexical (i.e. downtoners and consultative devices) and syntactic modifiers (i.e. the combination of syntactic modifiers). 


\section{Discussion}

This study asked (1) whether strategy instruction improves learners' ability to write appropriate email requests to professors, and if so, (2) in what features of the email discourse improvement is observed. Regarding the first research question, analysis of learners' overall performance to produce student-initiated email requests to faculty revealed that, after the intervention, learners improved markedly in structuring their email discourse and mitigating the tone of the email requests. Based on this evidence, the answer to research question 1 is positive. Thus, in line with the small number of studies in pragmatics that have used measures of appropriateness to validate the effects of instruction (Nguyen, 2018; Nguyen et al., 2015, 2019), these findings attest to the effectiveness of pragmatic intervention in improving learners' ability to produce email requests to faculty. However, the major novelty of this study lies in the teaching approach taken which, following Taguchi's (2018) recommendations, pursued strategy instruction to equip learners with the tools (i.e. self-directed learning strategies) to enhance their pragmatic performance in actual communication with their professors via email. These tools included a combination of cognitive and metacognitive strategies that enabled learners to (1) promote their reflective skills and develop different ways to interpret email requests to faculty, (2) direct learners' attention to the email requests they send naturally to their professors, and (3) set their own goals, plan their email writing and self-monitor their email performance. This practice coupled with the role of the teacher as facilitator and advisor, optimized the learning of the targeted pragmatic phenomenon (i.e. email requests to faculty). Therefore, this study adds to the field of instructed pragmatics by providing a new perspective on teaching pragmatics based on self-regulated learning, which implies a shift from a teacher-centred model to a learner-centred model.

Concerning the second research question, additional analyses were performed to determine learners' improvement in writing structural elements of email discourse (i.e. email subject lines, opening and closing sequences) as well as content elements (i.e. request strategies and internal request modifiers), which are discussed separately. As to the findings related to the structural components of the email, it is worth noting that before instruction, some learners wrote subject lines that did not relate to the content of the email. Moreover, learners were uncertain about how to write opening and closing sequences since they displayed a great variation in style. Focusing on email openings, many greetings used the deference form 'dear' followed by the wrong academic title (e.g. 'Mrs' instead of 'Professor') and the last/full name of the instructor, capable of causing offence (EconomidouKogetsidis, 2011). Moreover, the sender's self-introduction, the second part of the opening sequence, was rare. In terms of closings, as many as eight different closing combinations of different formal and informal moves were found, suggesting that learners were unsure about what combination could be the most appropriate to close an academic email.

Nonetheless, after the treatment, learners composed better and more concrete subject lines as well as complete and more appropriate opening and closing sequences. In the email openings, despite the fact that learners received instruction in both formal and informal greetings, they showed a preference for formality (i.e. Dear+Professor+last name/full name) and included an effective self-introduction, that is, they gave the sender's name and also provided information about the course they were in, which became a norm. With regard to email closings, a formal combination (i.e. Pre-closing +Complementary close +Signature) was found 
in the majority of the emails. It is worth noting that although the most common pre-closing included a thanks statement, other variations such as apologies (e.g. Sorry for bothering you) to mitigate the request imposition or appeals for actions (e.g. I look forward to hearing from you) were also observed but in a reduced number.

These findings support those of Chen (2015) and Nguyen (2018) who found that the structural elements of emails are amenable to instruction given their formulaic nature. Chen (2015) reported learners' gains in writing concrete subject lines, correct greeting constructions, complete self-identifications and correct closing moves after an instructional period on request emails to faculty. Alike, Nguyen (2018, p. 250) reported learners' benefits on writing opening and closing sequences after instruction although the author explained that those benefits were more evident in opening moves, given 'their transparent functional meaning (e.g. formality versus informality)'.

As for the findings concerning the content components of the emails, the present study found that prior to intervention, learners displayed a strong preference for direct requests realized by means of like/appreciate statements and performatives, despite making high imposition requests. Moreover, the request strategies did not rely on the use of internal mitigation, but on request grounders (i.e. justifications). These results show that learners patterned similarly to those analysed in previous studies on writing L2 email requests to faculty (Biesenbach-Lucas, 2007; Economidou-Kogetsidis, 2011, 2018) in their preference for direct strategies. In fact, this preference for directness reflects, as stated by Nguyen (2018), the learners' lack of awareness of the need to respect the principle of negative politeness (i.e. emphasis on distance between learners and professor) (Brown \& Levinson, 1987).

Analysis of post-instructional data revealed a move from preference of directness to conventionally indirectness, which involves less potentially face-threatening effects (Brown \& Levinson, 1987). Furthermore, requests were modified by various types of lexical and syntactic downgraders. Specifically, results revealed that after instruction learners were quite adept at utilizing the lexical modifiers of downtoners and consultative devices as well as the combination of syntactic modifiers (conditional, past tense, progressive aspect), which were not just frequent but varied. These changes could be related to an increased learners' awareness of how politeness works when communicating with higher ups in the academic context (Nguyen, 2018). These findings seem to confirm tendencies noted by previous instructional research (Chen, 2015; Nguyen, 2018). Chen, for instance, observed a moderate increase in the use of conventionally indirect strategies and internal request modifiers, the majority of them being syntactic modifiers realized by embedded constructions. The lexical modifiers of downtoners and consultative devices, however, were minimally used. Later, Nguyen (2018) reported a marked increase in the students' use of conventionally indirect strategies as well as syntactic modifiers, which were taught as an integral component of conventionally indirect request strategies. Unfortunately, time constrains prevented Nguyen from examining lexical modification as part of the instructional framework.

While only a small sample of emails was analysed, the findings provide evidence that learners, after the instructional period, resorted largely to query preparatory as their main request strategy and to syntactic and lexical modifiers to downplay the assertive voice of 
their email requests. Therefore, this study has shown that providing learners with the right tools and training, learners can improve their writing performance, specifically writing appropriate email requests to faculty, which poses a challenge to L2 learners (Savić, 2018).

\section{Conclusions}

The current study examined the effects of explicit strategy instruction on learners' production of naturally occurring email requests to faculty. Findings pointed out that pragmatic instruction helped them write more appropriate email requests by producing more concrete subject lines as well as complete and more formal email opening and closing sequences. Concerning requests, learners refrained from using unmodified direct requests after instruction, resorting instead to conventionally indirect requests that were modified through the use of combinations of syntactic modifiers and/or lexically modified by using downtoners and consultative devices.

However, these results should be interpreted with caution due to the limitations of the study, such as the lack of strategy use measurement and the absence of a control group. As for the former limitation, the impact of strategy instruction was examined on learners' ability to write appropriate email requests to faculty. Measures of learners' strategy use during the composition process were not collected as part of the present study. To address this limitation, future instructional studies could ask learners to complete a writing strategy questionnaire or interview to identify their writing behaviour and use of learning strategies during the writing process to understand the interplay between strategy use and writing performance.

The latter limitation is related to the design. Regrettably, the study lacked a control group to compare pragmatic gains in the learners' ability to produce appropriate email requests. A major challenge in collecting naturally occurring data is that the researcher cannot determine the sample size before data collection and must rely on the actual occurrences of the targeted pragmatic feature (Taguchi \& Roever, 2017), as it happened in this study. Thus, the study could be replicated with the inclusion of a control group (if natural data allow) to strengthen the results.

Despite the above-mentioned limitations, this study contributes to the field of instructional pragmatics by exploring the efficacy of strategy instruction on learners' ability to write appropriate emails to faculty. Although an under-research area in the field of pragmatics, strategy instruction may empower learners (i.e. give them more autonomy and responsibility in their own learning process) and facilitate the transfer of learned pragmatic knowledge to real life communication. Without doubt, strategy instruction has much room in future instructional pragmatics studies.

\section{Acknowledgements}

I would like to thank Dr. Alicia Martínez-Flor, from University Jaume I, for her help in the analysis of data. I would also like to thank the students who participated in this study and the anonymous reviewers who helped improve the paper. 


\section{Funding}

The author(s) disclosed receipt of the following financial support for the research, authorship, and/ or publication of this article: This study is part of the research project PID2020-117959GB-I00 funded by MCIN/ AEI /10.13039/501100011033. Additional funding has been granted by Generalitat Valenciana (AICO/2021/310), the Universitat Jaume I (UJI-B2019-23), and Projectes d'Innovació Educativa de la Unitat de Suport Educatiu 3975/21 and 3976/21.

\section{ORCID iD}

Esther Usó-Juan (iD https://orcid.org/0000-0003-4030-8926

\section{Note}

1. Unless otherwise specified, in this study the term L2 refers to the learning of another language after one's mother tongue (L1), regardless of whether it is learned in a second or foreign language context.

\section{References}

Alcón-Soler, E. (2013). Mitigating email requests in teenagers' first and second language academic cyber-consultation. Multilingua, 32, 779-799.

Alcón Soler, E. (2015). Pragmatic learning and study abroad: Effects of instruction and length of stay. System, 48, 62-74.

Alcón-Soler, E. (2017). Pragmatic development during study abroad: An analysis of Spanish teenagers' request strategies in English emails. Annual Review of Applied Linguistics, 37, 77-92.

Biesenbach-Lucas, S. (2007). Students writing e-mails to faculty: An examination of e-politeness among native and non-native speakers of English. Language Learning and Technology, 11, 59-81.

Bou-Franch, P. (2006). Solidarity and deference in Spanish computer-mediated communication: A discourse-pragmatic analysis of students' emails to lectures. In Bou-Franch, P. (Ed.), Ways into discourse (pp. 61-79). Comares.

Bou-Franch, P. (2011). Openings and closings in Spanish email conversations. Journal of Pragmatic, 43, 1772-1785.

Brown, P., \& Levinson, S. (1987). Politeness: Some universals in language usage. Cambridge University Press.

Byram, M. (1997). Teaching and assessing intercultural communicative competence. Multilingual Matters.

Chen, C.F. (2001). Making e-mail requests to professors: Taiwanese vs. American students. Unpublished paper presented at the Annual Meeting of the American Association for Applied Linguistics, St-Louis, MO, USA. ERIC Document Reproduction Service No. ED 461299.

Chen, C.F. (2006). The development of e-mail literacy: From writing to peers to writing to authority figures. Language Learning \& Technology, 10, 35-55.

Chen, Y. (2015). Developing Chinese EFL learners' email literacy through request to faculty. Journal of Pragmatics, 75, 131-149.

Codina-Espurz, V., \& Salazar-Campillo, P. (2019). Openings and closings in emails by CLIL students: A pedagogical proposal. English Language Teaching, 12, 57-67.

Economidou-Kogetsidis, M. (2011). 'Please answer me as soon as possible': Pragmatic failure in non-native speakers' e-mail requests to faculty. Journal of Pragmatics, 43, 3193-3215.

Economidou-Kogetsidis, M. (2016). Variation in evaluations of the (im)politeness of emails from L2 learners and perceptions of the personality of their senders. Journal of Pragmatics, 106, 1-19. 
Economidou-Kogetsidis, M. (2018). 'Mr Paul, please inform me accordingly' address forms, directness and degree of imposition in L2 emails. Pragmatics, 28, 489-515.

Félix-Brasdefer, J.C. (2012). E-mail request to faculty: E-politeness and internal modification. In Economidou-Kogetsidis, M., \& H. Woodfield (Eds.), Interlanguage request modification (pp. 87-118). John Benjamins.

Ford, S. (2006). The use of pragmatics in E-mail requests made by second language learners of English. Studies in Language Sciences, 5, 143-162.

Hartford, B.S., \& Bardovi-Harlig, K. (1996). 'At your earliest convenience': A study of written requests to faculty. In Bouton, L. (Ed.), The pragmatics and language learning monograph series: Volume 7 (pp. 55-69). University of Illinois at Urbana-Champaign.

Hendriks, B. (2010). An experimental study of native speaker perceptions of non-native request modification in e-mails in English. Intercultural Pragmatic, 7, 221-255.

Hofstede, G., \& Hofstede, G.J. (2005). Edition: Cultures and organizations: Software of the mind. 2nd edition. McGraw-Hill.

Hyland, K. (2003). Second language writing. Cambridge University Press.

Martínez-Flor, A., \& Usó-Juan, E. (2020). Teaching speech acts in a second language. In Schneider, K.P., \& E. Ifantidou (Eds.), Developmental and clinical pragmatics (pp. 269-300). Mouton de Gruyter.

Nguyen, T.T.M. (2018). Pragmatic development in the instructed context. A longitudinal investigation of L2 email requests. Pragmatics, 28, 217-252.

Nguyen, T.T.M, Do, T.T.H., Nguyen, T.A., \& Pham, T.T.T. (2015). Teaching email requests in the academic context: A focus on the role of corrective feedback. Language Awareness, 24, $169-195$

Nguyen, T.T.M, Do, T.T.H., Pham, T.T.T., \& Nguyen, T.A. (2019). The effects of corrective feedback with and without revision on enhancing L2 pragmatic competence. Applied Pragmatics, $1,1-25$.

Oxford, R. (1990). Language learning strategies. Newbury House.

Oxford, R. (2011). Teaching and researching language learning strategies. Pearson Education.

Savić, M. (2018). Lecturer perceptions of im/politeness and in/appropriateness in student e-mail requests: A Norwegian perspective. Journal of Pragmatics, 124, 52-72.

Schmidt, R. (1993). Consciousness, learning and interlanguage pragmatics. In Kasper, G., \& S. Blum-Kulka (Eds.), Interlanguage pragmatics (pp. 21-42). Oxford University Press.

Taguchi, N. (2015). Instructed pragmatics at a glance: Where instructional studies were, are, and should be going. State-of-the-art article. Language Teaching, 48, 1-50.

Taguchi, N. (2018). Pragmatic competence in foreign language education: Cultivating learner autonomy and strategic learning of pragmatics. In Walter, I., Chan, D., Nagami, M., \& C. Bourguignon (Eds.), New perspectives on the development of communicative and related competence in foreign language education (pp. 53-69). Mouton de Gruyter.

Taguchi, N., \& Roever, C. (2017). Second language pragmatics. Oxford University Press.

Taguchi, N., Tang, X., \& Maa, J. (2019). Learning how to learn pragmatics: Application of selfdirected strategies to pragmatics learning in L2 Chinese and Japanese. East Asian Pragmatics, $4,11-36$.

University of Cambridge Local Examinations Syndicate (UCLES). (2001). Cambridge IELTS with answers 2: Examination papers from University of Cambridge Local Examinations Syndicate. Cambridge University Press.

Zhu, W. (2012) Polite requestive strategies in emails: An investigation of pragmatic competence of Chinese EFL learners. RELC Journal, 43, 217-238. 